\title{
GEOMORFOLOGIA E PEDOLOGIA
}

José Pereira de Queiroz Neto*

\section{RESUMO}

Este trabalho procura discutir questões que, a princípio, parecem obvias como o que é geomorfologia e pedologia, mas que quando do trato acadêmico revelam sua complexidade e discussão sobre seu entendimento e ação. Para isso um breve recuperar histórico de seu entendimento e sua utilização se fez necessário bem como as relações que se estabelecem entre Geomorfologia e Pedologia.

\section{PALAVRAS CHAVE}

Geomorfologia, Pedologia, ciência, solos

\section{ABSTRACT}

This paper intends to discuss subjects that seems obvious at first, as what is Geomorphology and Pedology, but when, in academic work, they reveal their complexity and discussion about their understanding and action. For that, a brief historical recover of their understanding and their utilization have become necessary as well as the relations established between geomorphology and Pedology.

\section{KEY-WORDS}

Geomorphology, Pedology, science, soil.

\section{Algumas questões surgem tão logo ouvimos ou lemos essas duas palavras:}

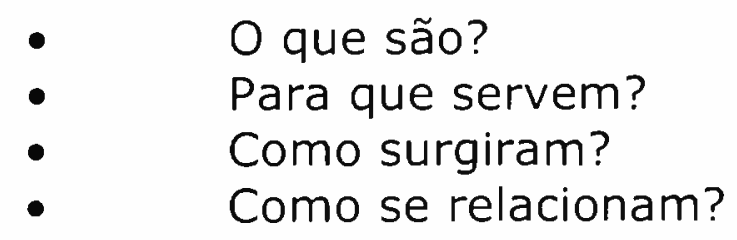

\begin{abstract}
Em primeiro lugar, vamos ver o que são esse dois ramos do conhecimento.
\end{abstract}

Pedologia ( do grego e latim ped ou pedon $=$ terra onde se pisa, logos = estudo) é um termo erudito, criado para designar o ramo do conhecimento das Ciências da Natureza que estuda 
os solos: é interessante verificar que a importância do relevo para estes achase explicitada na própria definição dos fatores responsáveis pela sua gênese.

O termo Geomorfologia (do latim geo $=$ terra, morfo $=$ forma, logos $=$ estudo) também é erudito e recente, designando o ramo do conhecimento das Ciências da Natureza que estuda as formas dos relevos. Ao contrário da Pedologia, que situa o relevo na sua conceituação de solo, a importância ou o papel que este desempenharia para os relevos não foram nunca colocados de modo explícito pela Geomorfologia.

A seguir, vamos tentar responder por partes às outras questões: de início, as suas histórias = como e quando e surgiram como ramos do conhecimento das Ciências da Terra. A seguir, como se relacionam, começando pelo seu reconhecimento recíproco, porém independente dentro de cada conhecimento. Terminaríamos comentando como deveriam se relacionar (e o verbo está no condicional, porque nem sempre pedólogos e geomorfólogos conseguem se entender adequadamente).

\section{Pequenas Histórias}

A preocupação com o conhecimento dos solos acha-se registrada desde os tempos históricos e isso é fácil de se entender: a partir do momento em que os homens passaram a cultivar plantas, logo procuraram reconhecer as melhores terras para seus cultivos. Mas próximos a nós vamos encontrar verdadeiros tratados escritos na Roma dos Cesares sobre agricultura, incluindo informações sobre a qualidade dos solos e como reconhecê-los.

No Renascimento, além das navegações que alargaram as fronteiras do mundo até atingir o que é hoje, a busca pelos princípios da vida colocavam o solo em situação privilegiada. Acusavase o ar, a água, o fogo e flogística como os grandes responsáveis pela vida no nosso planeta: a participação da terra, do solo, ora tinha tanto destaque como os outros, ora era negligenciada.

O final do século XVIII e início do XIX terá enorme importância para o reconhecimento da importância dos elementos químicos na nutrição das plantas. Duas correntes se enfrentam, de uma lado o francês BOUSSINGAULT, afirmando que as matérias orgânicas seriam essenciais para o desenvolvimento vegetal, de outro alemão LIEBIG, que demonstra a importância da nutrição dita mineral, envolvendo os elementos químicos presentes nos solos. Este último ganhou a parada, e de tal forma que até hoje as adubações que se praticam nas diferentes culturas baseiam-se em princípios por ele estabelecido. No entanto, de uns tempos para cá começouse a perceber que BOUSSINGAULT não estaria totalmente errado, pois para manter um solo saudável e produtivo, é imperioso manter equilibradas as relações entre suas partes mineral e orgânica.

Em 1883, aparece o livro Chernozem (do russo Tcherno = negro e zem $=$ solo) de DOKUTCHAEV, que constituiu a certidão e batismo da moderna Ciência dos Solos: ele fora contratado pelo governo russo para estudar as causas do fracasso da colheita de trigo nas terras negras na Ucrânia. 
Logo depois, ele estuda outro solo em região mais ao norte, o podzol, cujo o nome deriva do aspecto de seu horizonte subsupercial $($ pod $=$ sob, zol = cinza da queima da madeira). A importância desses trabalhos do cientista russo, é que pela primeira vez foi reconhecida a sucessão de horizontes $A, B$ e $C$ dos solos, suas características químicas e físicas, e procurou-se relacionar com a origem e evolução dos solos.

É curioso observar que também antes do final do século XIX, HILLGARD nos Estados Unidos chega a percepções bastante próximas, organizando o reconhecimento e o mapeamento de solos, sobretudo das frentes pioneiras, a partir de suas qualidades e características (textura, cor, análises de solos/ nutrientes).

Percebe-se, assim, que o estudo dos solos teve sempre um caráter utilitarista, e seu reconhecimento e as definições de suas propriedades foram sempre feitos com rigor analítico. Esses dois aspectos irão marcar todo o desenvolvimento da Pedologia, até hoje, diferenciando-o do da Geomorfologia.

Certos aspectos da superfície da terra chamaram desde cedo a atenção dos homens, principalmente o trabalho das águas correntes (rios, erosão). Ressalte-se, nessa época, os escritos do gênio eclético LEONARDO DA VINCI, que publicou escritos sobre erosão.

No Renascimento estava-se descobrindo que a Terra é redonda, permitindo as navegações que "descobriram" novos continentes, inclusive as de circunavegação. Para isso, o conhecimento dos oceanos era importantíssimo, da mesma forma que para as excursões terrestres e ocupação dos territórios era importante o conhecimento dos cursos d'água e sua dinâmicas, dos ventos e do gelo.

O final do século XVIII e início do século XIX foram efetuadas observações sistemáticas sobre a ação das correntes alpinas, na região de Chanonix na França, e sobre processos e mecanismos da erosão nas Montanhas Rochosas, na região de Salt Lake City nos Estados Unidos. É importante lembra que as Geografia e Geologia modernas também estavam nascendo, e iriam determinar dois caminhos diferentes, a serem trilhados pela Geomorfologia: nos Estados Unidos, a denominada Geografia Física tornase um ramo das Ciências Geológicas, enquanto na Europa, sobretudo na França, a Geografia como um todo passa a integrar as Ciências Humanas.

No final do século XIX as observações sistemáticas das formas do relevo permitiram a DAVIS o estabelecimento das bases da moderna Geomorfologia. Esta nasce inclusive, com um método de trabalho e um modelo teórico de interpretação da gênese e evolução das formas de relevo, a teoria dos ciclos de erosão. O método de trabalho inicial da Geomorfologia fora a descrição das formas do relevo, o que levaria à criação de modelos teóricos razoavelmente abstratos e analógicos.

Se o estudo de certos aspectos da Geomorfologia teve, pelo menos parcialmente, um caráter utilitarista quando, por exemplo, procurava conhecer a dinâmica e funcionamento das águas correntes, a explicação da gênese e evolução das formas dos relevos seria feita através de um modelo teórico, 
numa abordagem sintética, diversa $e$ sem o rigor da abordagem analítica da Pedologia.

Os desenvolvimentos dos conhecimentos na Geomorfologia e na Pedologia sempre estiveram relacionados a problemas surgidos no uso das terras. Percebia-se que sem o conhecimento das características e qualidades dos solos, seu uso não poderia ser adequado para obter melhores produções agropecuárias, além de poder tornar-se danoso para o ambiente: a ocupação do espaço perderia o rumo. Para a Geomorfologia, dava-se importância somente ao reconhecimento de certos processos, como por exemplo os fluviais que determinam inundações, erosões marginais, deposição de sedimentos.

Assim, o rigor analítico empregado no conhecimento dos solos e de seus materiais constituintes sempre fez parte do desenvolvimento da Pedologia: apenas como lembrança, hoje empregam-se equipamentos com enorme poder de aumento, que permitem enxergar a superfície de partículas de argila (que são menores que 0,002 mm). Esse rigor nunca fez parte do desenvolvimento da Geomorfologia, que foi dominado por técnicas de descrição e qualificação das formas de relevo, cujas escalas de observação evidentemente não são as mesmas das empregadas no estudo dos solos: são no máximo escalas $1: 1$, isto é, da dimensão registrada pela visão humana.

\section{Que Relações elas mantém entre si?}

$\begin{array}{rcc}\text { BÜDELL } & (1968) & \text { propôs uma } \\ \text { interpretação astuciosa para definir a }\end{array}$

composição e estrutura do planeta; a Terra seria formada por 7 envelopes sucessivos:

- o interior, tridimensional, com material ígneo, alta pressão e temperatura, conferindo grande mobilidade às moléculas (grão e núcleo = NIFE; manto = SIMA);

- a litosfera, tridimensional e contínua, crosta rígida, com muito baixa mobilidade das moléculas (SIAL);

- a pedosfera, tridimensional e descontínua, ocorre apenas na parte emersa da crosta, apresenta mobilidade de moléculas superior à da litosfera;

- a hidorsfera, tridimensional e descontínua por entre espaços deixados pela pedosfera, apresenta moléculas em movimento;

- a cirosfera, tridimensional e descontínua, ocorrendo apenas nos pólos e altas montanhas, constituida por água em estado sólido, portanto com pouca mobilidade das moléculas;

- a atmosfera, tridimensional e descontínua, em estado gasoso com grande mobilidade das moléculas;

- enfim, a superfície, seria uma espécie de envelope apenas bidimensional e contínuo, sem moléculas (sem matéria), correspondendo às formas de relevo tanto sobre os continentes quanto no fundo dos oceanos.

Faltaria nessa sucessão de envelopes a biosfera, que é tridimensional e descontínua, em estado sólido no exterior e líquido e gasoso no interior, situa-se na interface da pedosfera e da atmosfera.

É curioso observar que as formas dos relevos tem debaixo de si os solos, 
Geomorfologia e Pedologia deveriam manter estreitas relações, assim como as que ambas mantém com a Geologia, que está debaixo. No entanto, como já havíamos mencionado, historicamente, não foi isso que ocorreu, pois o estudo dos solos e dos relevos desenvolveuse de modo interessante e autônomo e por caminhos raramente paralelos: os procedimentos empregados, desde o início, no reconhecimentos de seus objetivos de estudo eram muito diferentes e as linguagens muito específicas. A bem dizer, só a partir da $2^{a}$ metade do século XX foram estabelecidas relações íntimas entre esses dois ramos do conhecimento: um dos problemas a superar diz respeito às diferenças entre procedimentos de abordagem e o outro, conseqüência do primeiro, é a questão da escala de abordagem no estudo dos respectivos objetos de estudo. As diferenças dos procedimentos empregados na abordagem do estudo dos solos e dos relevos são facilmente compreensiveis.

Em primeiro lugar, as raízes das plantas cultivadas exploram terra: é preciso conhecer suas características e propriedades, sobretudo analisá-la, conhecer o nivel dos nutrientes através das análises de laboratório. Além disso, a descoberta de DOKUTCHAEV foi fundamental: os solos apresentam camadas sucessivas, mais ou menos paralelas à superfície (de onde o nome horizontes) e só o conhecimento dessa organização permite avaliar o potencial de fertilidade (água e nutrientes) de um solo. Dessa forma, só se conhece o solo se abrirmos um "buraco" de profundidade adequada, para observar a totalidade de sua organização: seria necessário
- reconhecimento dessa organização juntamente com o conhecimento de suas características analíticas.

A simples observação da superfície, de acordo com a definição de BÜDELL, seria suficiente para se identificar 0 relevo. A partir do modelo proposto por DAVIS, interpretando a gênese e evolução dos relevos, as observações efetuadas em regiões muito diversas fez surgir a idéia de que cada clima seria responsável por um modelo de relevo (glacial, desértico, úmido, temperado e tropical, etc.). As teorias iniciais empregadas para reconhecer as diferentes formas dos relevos eram apenas descritivas - para conhecer o relevo, bastava descrevê-lo: esse reconhecimento poderia ser acompanhado de medidas que procuravam qualificá-lo, como comprimento das vertentes, profundidade dos vales, largura das planícies aluviais, etc.

Nos anos 30 do século $X X$, a Pedologia começaria a perceber a existência de relações de dependência entre a história dos solos e a posição ocupada nos relevos onde se encontram. Inicialmente, a posição topográfica determinaria uma ação diferenciada da água sobre características dos solos. Seguir-se-ia a percepção de que, mantidas as mesmas condições, essa ação da água determinaria uma dostribuição constante dos solos nas encostas; dessa época data a proposta do termo catena por MILNE que, trabalhando com mapeamento de solos em território africano, observara que nuna dada região as encostas apresentariam um sucessão repetitiva de solos nas encostas; esse termo seria empregado a seguir também 
pelos geomorfólogos. Posteriormente, percebe a relação entre tipos de solos e formas de relevo, distinguindo que solos mais "jovens" ocorrem sobre relevos de evolução recente. Finalmente, a partir das duas últimas décadas do século XX, alguns pedólogos começam a perceber que a alteração das rochas pelo intemperismo e a formação dos solos são poderosos agentes na formação de formas do relevo.

Por seu lado, somente na segundo metade do século XX, a Geomorfologia passou a perceber a importância do conhecimento dos produtos do intemperismo (solos, alteritas, formações superficiais) como testemunhos de processos de gênese e evolução das formas de relevo. No entanto, o passo seguinte dado pela Pedologia, no reconhecimento de que a gênese de solos é um poderoso instrumento de gênese de relevos, raramente foi dado por geomorfólogos: ainda perdura a idéia que a gênese dos relevos é conseqüência apenas de processos erosivos. e que a dos solos apenas fornece materiais para serem erodidos.

\section{Escalas e Classificações}

O segundo problema a superar, como mencionado, é a questão das escalas temporais e espaciais no estudo de seus objetos.

O estudo dos solos e dos relevos encontram-se no ponto de encontro de vários ramos do conhecimento, que apresentam escalas temporais muito diversas:

Litosfera - como é o envelope mais rígido com moléculas de baixa mobilidade, a evolução é muito lenta, deixando registros que podem atingir até o bilhão de anos.

Pedosfera - moléculas com alguma mobilidade e evolução menos lenta, deixando registros de sua evolução que podem atingir os milhares ou centenas de milhares de anos.

Biosfera - moléculas de maior mobilidade, deixam registros de sua presença e evolução de até centenas de anos.

Superfície - depende das outras esferas: não tenho moléculas próprias, pode apresentar grande mobilidade (mudança de forma por erosão, por exemplo) ou menor (manutenção da forma juntamente com os solos), deixando registros desde contemporâneos até da ordem do milhar ou da centena de milhar de anos.

Atmosfera - moléculas de grande mobilidade, apresentam natureza essencialmente contemporânea, praticamente não deixando registros diretos de sua evolução.

Seria preciso acrescentar a influência do homem em todos os fenômenos de superfície, que poderia ser entendida como constituindo uma antroposfera, que acarretaria grande aceleração dos processos, portanto maior mobilidade das moléculas, deixando registros de até alguns milhares de anos.

Dessa Forma, o estudo dos solos relevos deve levar em conta a compatibilização dessas escalas temporais.

O problema das escalas espaciais está diretamente relacionado ao das 
classificações. Por exemplo a Pedologia tradicionalmente classifica seu objeto de estudo como um corpo natural bem definido, tridimensional, que corresponde ao menor tamanho contendo todas as características morfológicas: sucessão vertical de horizontes, extensão lateral que abarque as variações de espessura; em geral isso corresponde às dimensões de uma trincheira com dois a três metros de comprimento e largura e pelo menos dois metros de profundidade. De um lado, a observação e a definição desse objeto podem ser feitas em qualquer escala, desde 1:1 até escalas muito pequenas. De outro lado, a classificação dos solos se faz através de uma hierarquização de categorias, reunido cada nível categórico solos com características afins, indo das características específicas, na base, às mais gerais, no topo da classificação, de modo similar às das taxonomias botânicas e zoológica. Assim, a representação cartográfica da distribuição dos solos numa região dependerá da escala da carta; por exemplo, uma carta de solos na escala 1:100.000 só poderá representar uma determinada associação ou agrupamento de solos correspondendo à um determinado nível de hierárquico e não mais aos perfis individuais.

Para a Geomorfologia, o objeto de estudo não é passivel de ser definido dimensionalmente. Um exemplo interessante é o de uma escarpa de cuesta: ela só pode ser definida como tal a partir da observação à uma certa distância, que permite enxergá-la no seu todo - isso corresponde à uma determinada escala de observação, menor que 1:1. A observação cada vez mais próxima, permite enxergar detalhes cada vez mais precisos, porém com perda da visão do conjunto: um exemplo significativo, no sudeste brasileiro, é o da cuesta de Botucatu, que vai dos confins do SSW de Minas Gerais até penetrar pelo NNE do Paraná. Em escalas maiores, é possível caracterizar trechos dessa cuesta, mas a representação do todo só será possível em escala muito pequena.

$$
\text { As legendas das cartas }
$$

geomorfológicas, de modo geral, contém esboços de classificações dos fatos observados. Cabe a TRICART (1965) a unica proposta de classificação taxonômica dos fatos geomorfológicos, aliás muito astuciosa pois procura compatibilizar as escalas temporais e espaciais, hierarquizando-as desde o nível mais geral, dos continentes, até o mais particular das figuras microscópicas; essa proposta de taxonomia foi utilizada por BERTRAND, na sua tentativa de definição geossistêmica de paisagem. No entanto se essa taxonomia compreende os fatos geológico-estruturais e morfológicos hierarquizados, não contempla as alteritas, as formações superficiais ou os solos.

Pelo exposto, percebe-se que o estabelecimento de relações espaçotemporais diretas entre os objetos solo e formas do relevo_ não é tarefa fácil. Esse tipo de abordagem permite, quando muito, estabelecer relações de coincidência de aparecimento, isto é, perceber que determinada categoria de solo pode aparecer simultaneamente à um tipo de relevo. Essas relações de coincidência independem das escalas de observação e representação: no entanto, por si só elas não conseguem explicar as causas do aparecimento conjunto 
de determinado solo com determinada forma de relevo.

\section{Busca do Entendimento}

\section{$\mathrm{Na}$ procura da compreensão} das relações entre os solos e os relevos é preciso superar certas idéias preconcebidas, a principal delas que diz haver uma oposição entre os processo de pedogênese (alteração das rochas, formação dos solos) e de morfogênese (erosão, esculturação/esculpimento das formas de relevo): ambos podem ser simultâneos e, mais que isso, podem agir concomitantemente.

$\mathrm{Na}$ realidade, a busca do entendimento das relações entre os dois objetos, solo e relevo, passa pela compreensão dos processos dinâmicos (intemperismo) que agem na parte superficial da crosta, responsáveis pela elaboração dos relevos e gênese dos solos, isto é, morfogênese (entendida como processos erosivos) e da pedogênese (entendida como processos bioquímicos relacionados à alteração das rochas).

\section{Para tanto, é preciso ter em mente que:}

- Quanto menor a escala espacial de observação/representação de um fenomeno contínuo, mais lenta é sua transformação (dinâmica), mais fácil é o conhecimento de relações de coinscidência de posição. Um exemplo interessante é o de grupamentos de solos e de famílias de relevo que acompanham as relações regidas pela zonalidade: entram aqui apenas características e propriedades de elevado grau de generalização, que permitem mostrar que ao clima de savana correspondem formas de relevo tipo chapadas e solos do tipo latossólico.

- Quanto maior a escala de observação/ representação de um fenômeno, mais rápidas são suas transformações, mais fácil é a compreensão dos processos que thes dão origem e que permitem explicar as eventuais coincidências de posição. Exemplos significativos podem ser encontrados nas pesquisas sobre os caminhos da água nas vertentes, tanto internamente aos solos (alteração das rochas, transporte de matéria como partículas). Essas pesquisas mostram o importante papel das ações químicas. Físicas e físico-químicas da água, e biológicas dos organismos vivos, na alteração das rochas/formação dos solos, com a liberação de elementos, permitem explicar as eventuais coincidências de posição. Exemplos siginificativos podem ser encontrados nas pesquisas sobre os caminhos da água nas vertentes, tanto internamente aos solos (alteração das rochas, transporte de matéria sob forma iônica), quanto externamente pela superfície (erosão, transporte de matéria como partículas). Essas pesquisas mostram o importante papel das ações químicas, físicas e físico-químicas da água, e biológicas dos organismos vivos, na alteração das rochas/formação dos solos, com a liberação de elementos, com as transformações mineralógicas e com a evacuação de grande parte deles: essas ações dão lugar a abatimentos superficiais localizados e podem originar formas de relevo sem a intervenção dos processos erosivos superficiais.

Como idéia final, pode-se afirmar que a escala de abordagem para a 
compreensão das relações entre os solos e os relevos deve ser compatível com a magnitude do fenômeno a ser estudado, que no caso é a vertente.

\section{Autores citados por ordem de aparecimento no texto}

BOUSSINGAULT, Jean Baptise (18011887) - químico francês, estudo a ação dos fertilizantes de origem orgânica na nutrição das plantas, estabelecendo polêmica com o alemão Justus von LIEBIG, que introduziu a Química mineral como principal fator de alimentação das plantas.

\section{LIEBIG, Justus von (1803-1873)}

- químico alemão, estebelcendo em 1840 a denominada "lei do mínimo", segundo a qual o fator limitante do crescimento dos vegetais é o elemento nutritivo essencial que aparece com a menor concentração relativa.

DOKUTCHAEV, Vassili Vassilievitch (1843-1903) - geógrafo e naturalista, criador da moderna Ciência do Solo (1883 $\rightarrow$ Os Chermozems). com seus trabalhos, propôs a disposição zonal dos solos e a análise sintética do meio geográfico.

HITNEY, Milton (18 ?- 19 ?) O geólogo americano, dedicou-se ao mapeamento dos solos em diferentes escalas, criando a divisão de Solos no Departamento de Agricultura daquele país, tendo preparado para a exposição Internacional de Chicago (1893) uma coleção de 1.500 exemplos de solos $(1893 \rightarrow$ The Soils of Maryland).
LEONARDO DA VINCI (1452-1519)

- engenheiro militar, arquiteto, escultor e pintor italiano, mais conhecido pelo quadro da "Mona Lisa"do que por suas observações sobre hidraúlica e geologia.

DAVIS, Willam Morris (1850-1854) - geógrafo e geólogo americano, controvertido autor de Geografia Física, propôs $(1889 \rightarrow$ The rivers valleys of Pennsylvania) os conceitos de "ciclo de erosão"e de "peneplano"

BÜDELL, Julius (19 ?) -geomorfólogo alemão, notalizou-se por ter proposto o princípio das "regiões morfogenéticas"(1944), que levou mais à conceituação da "Geomorfologia climática"(1963); propôs também (1957) a teoria da "dupla superficie geomorfológica" = echplanação.

MILNE, G. (19 ? ) - pedológo britânico realizando mapeamento de solos na África Equatorial na década de 1930, percebeu que os perfis de solo aparecem nas encostas numa sucessão constante, presos entre si por fatores genéticos como os elos de uma corrente, daí o nome catena, que sugeriu para designar tais sucessões $(1935 \rightarrow$ Some suggested units of classification and mapping, particularly for East African Soils.

TRICART, Jean (1920) - geógrafo e geomorfólogo contemporâneo francês introduziu a análise dos depósitos sedimentares no estudo das formas do relevo, enfatizando também a ação do clima $(1977 \rightarrow$ Terra: planeta vivo); foi assessor do Projeto Radam, posteriormente RADAMBRASIL.

BERTRAND， G. (19 ?) - geógrafo contemporâneo francês principal 
responsável pela introdução do conceito de geossistema na Europa Ocidental
(1968 $\rightarrow$ Paysage et géographie phisique globale, traduzido por Olga Cruz 1971).

Texto aceito em fevereiro de 2003 